DOI: https://dx.doi.org/10.21123/bsj.2020.17.1(Suppl.).0199

\title{
Biomarker Significance of Serum CXCL8, CXCL10 and CXCL16 in Breast Tumors of Iraqi Patients
}

\author{
Aseel F. Khalaf ${ }^{1}$
}

\author{
Munawar A. Al-naqqash ${ }^{2}$ \\ Ali H. Ad'hiah
}

Nada A.S. Alwan ${ }^{3}$

Received 16/2/2019, Accepted 16/9/2019, Published 18/3/2020

This work is licensed under a Creative Commons Attribution 4.0 International License.

\begin{abstract}
:
The biomarker significance of three chemokines (CXCL8, CXCL10 and CXCL16) was evaluated in sera of 45 breast cancer (BC) and 28 benign breast lesion (BBL) patients, as well as 20 control women. Clinical stage and tumor expression of estrogen (ER), progesterone (PgR) and human epidermal growth factor receptor-2 (HER-2) receptors were considered in this evaluation. The results demonstrated that CXCL8, CXCL10 and CXCL16 showed a significant increased median in BC and BBL patients compared to control (CXCL8: 47.3 and 25.7 vs. 15.0; CXCL10: 37.6 and 30.7 vs. 13.1; CXCL16; 27.9 and 25.2 vs. 19.2 $\mathrm{pg} / \mathrm{ml}$, respectively). The increased levels of CXCL8 and CXCL16 were more pronounced in triple-negative and HER-2 positive patients, respectively. Binary logistic regression analysis revealed that CXCL8 was a significant predictor of $\mathrm{BC}$, and such prediction was more depicted in triple-negative patients. The receiver operating characteristic analysis also revealed that CXCL8 recorded an area under curve of 0.998 in BC patients. In conclusion, CXCL8 is a potential biomarker for BC, especially when ER, PgR and HER-2 expression is considered. In this context, the predictive significance of CXCL8 in influencing BC progression is suggested in triple-negative patients.
\end{abstract}

Key words: Breast cancer, Benign breast lesion, CXCL8, CXCL10, CXCL16.

\section{Introduction:}

Breast cancer $(\mathrm{BC})$ is the most common cancer in women and it is a late-stage disease that shows a high morbidity and mortality rates. In 2012, $1,671,149$ new cases of BC were diagnosed worldwide, with 521,907 death-related cases (1). In Iraq, $\mathrm{BC}$ is the commonest type of female cancers and in 2012, 4,115 cases were reported, accounting for approximately $30 \%$ of the registered cancers in women (2).

There are different BC-associated risk factors; for instance, gender, estrogen, family history, aging, multiple gene mutations and lifestyle, which can increase the risk of developing such female malignancy (3).

${ }^{1}$ Department of Biotechnology, College of Science, University of Baghdad, Baghdad, Iraq.

${ }^{2}$ College of Medicine, University of Baghdad, Baghdad, Iraq.

${ }^{3}$ National Cancer Research Center, University of Baghdad, Baghdad, Iraq.

${ }^{4}$ Tropical-Biological Research Unit, College of Science, University of Baghdad, Baghdad, Iraq *Corresponding author:

dr.ahadhiah@sc.uobaghdad.edu.iq

*ORCID ID: 0000-0002-2445-2242
However, host immunity can also increase (promotive) or decrease (suppressive) BC growth, and such immune-editing pathways are a dynamic process, in which tumor cells and the host immune response are involved, and marked by inflammatory reactions. Inflammation, therefore, plays a critical role in tumor onset, development, angiogenesis, and cell migration, and cytokines have been suggested to exert an important role in each event of $\mathrm{BC}$ progression (4).

Chemokines are members of a superfamily of chemotactic cytokines initially characterized because of their association with inflammatory responses via stimulation of leukocyte migration and adhesion during inflammation. They also influence other cellular functions especially those that are related to tumor progression; for instance, proliferation, angiogenesis, malignant transformation and cancer metastasis (5). In BC, chemokines have been reported to be associated with the enhancement of a pro-tumoral microenvironment and can direct metastasis in the breast. They are also involved in BC progression; favoring growth and proliferation of local tumor cells (6). Several chemokines and chemokine 
receptors have been suggested to participate in these processes (7), and CXCL8, CXCL10 and CXCL16 are three important chemokines that may have a role in the establishment of malignancy in female breast.

CXCL8, also known as interleukin-8 (IL-8), is a member of the angiogenesis/inflammationrelated chemokines that are secreted by endothelial cells and fibroblasts (stromal cells) and cells of tumors (8). It has tumor-promoting role, which is mediated through autocrine and/or paracrine actions, and furthermore, recent investigations highlighted its potential as a prognostic and/or predictive biomarker for cancer (9). In BC, there is cell line-based evidence that suggests a strong correlation between CXCL8-ectopic expression and breast carcinoma metastatic potential. Undifferentiated and highly metastatic cell lines have been shown to release much more CXCL8 than their differentiated and lower metastatic cells (10).

CXCL10, also known as IP-10 (interferon- $\gamma$ inducible protein 10), is a leukocyte chemoattractant chemokine that is produced by different cells (polymorphonuclear cells, monocytes, epithelial, keratinocytes and endothelial cells) in response to interferon-gamma (IFN- $\gamma$ ) (11). In relation to tumor progression, CXCL10 has been shown to have tumor-promoting function (12). In BC patients, a significant increased serum level of CXCL10 has recently been reported and its role in pathogenesis of breast malignancy has been suggested (13).

CXCL16 is a further chemokine that prompts migration of leukocytes expressing its receptor (CXCR6). Such chemokine has been on focus that is related to cancer progression because migration and metastasis of cancer cells share the patterns of leukocyte trafficking (14). Various cancers (for instance, prostate and pancreatic cancer) have been shown to express CXCL16, and in BC, it has been demonstrated that CXCL16 play an important role in the development of such malignancy (15).

With the objective of evaluating whether the three chemokines could have biomarker significance in $\mathrm{BC}$, the present study examined serum levels of CXCL8, CXCL10 and CXCL16 in Iraqi patients with such malignancy. The serum level was correlated with clinical stage of tumor and its immunohistochemical expression of estrogen (ER), progesterone (PgR) and human epidermal growth factor receptor-2 (HER-2) receptors.

\section{Materials and Methods: Patients and control}

The study was approved by the Ethics Committee at the Iraqi Ministry of Health. It involved 63 women with breast tumor, and according to the type of tumor, they were distributed as $\mathrm{BC}$ and benign breast lesion (BBL) groups. The first included 45 patients, while the second composed of 28 patients. The age range of BC patients was $25-76$ years (mean \pm standard deviation: $50.6 \pm 12.2$ years), while such range in BBL patients was $16-52$ years $(33.1 \pm 9.7$ years $)$. The patients were referred to the Oncology Teaching Hospital in Baghdad during March 2016 March 2017. The diagnosis was made by the consultant medical staff, which was based on physical breast examination, ultrasonography, with or without mammography and fine needle aspiration cytology (Triple Assessment Technique). Based on the histopathological examination, all BC tumors were grouped under invasive ductal carcinoma (IDC), while BBLs were fibroadenoma. The TNM (Tumor-Node-Metastasis) system was employed to determine the clinical stage of BC. It was based on three major morphological features: tumor size $(\mathrm{T})$, regional lymph node involvement $(\mathrm{N})$ and distant metastases (M). Based on such system, three clinical stages (I, II and III) were identified (16), but for the purpose of statistical analysis, stages I and II were considered as one group. The BC tumors were also characterized in terms of their immunohistochemical expression of ER, PgR and HER-2 receptors (Table 1). In addition to patients, 20 apparently healthy married women were included in the study (control group), and their age range was 20 - 45 years $(32.1 \pm 7.1$ years $)$.

Table 1. Clinical and laboratory data of patients diagnosed with breast cancer.

\begin{tabular}{|c|c|c|c|}
\hline Data & $\mathrm{N}(\%)$ & Data & $\mathrm{N}(\%)$ \\
\hline Tumor size & & $E R$ & \\
\hline $\mathrm{T} 1, \mathrm{~T} 2$ & $38(86.4)$ & expression & $32(71.1)$ \\
\hline T3, T4 & $6(13.6)$ & $\begin{array}{l}\text { Positive } \\
\text { Negative }\end{array}$ & $13(28.9)$ \\
\hline Regional lymph & & $P g R$ & \\
\hline node & $33(73.3)$ & expression & $30(66.7)$ \\
\hline $\begin{array}{l}\text { involvement } \\
\text { Present } \\
\text { Absent }\end{array}$ & $12(26.7)$ & $\begin{array}{l}\text { Positive } \\
\text { Negative }\end{array}$ & $15(33.3)$ \\
\hline Distant & & HER-2 & \\
\hline metastasis & $33(73.3)$ & expression & $22(48.9)$ \\
\hline Present & $12(26.7)$ & Positive & $23(51.1)$ \\
\hline Absent & & Negative & \\
\hline Clinical stage & & Triple- & $4(8.9)$ \\
\hline I, II & $21(60.0)$ & negative & \\
\hline III & $14(40.0)$ & expression & \\
\hline
\end{tabular}




\section{Methods}

Blood samples were collected from participants and serum was obtained by centrifugation. The sera were stored at $-20{ }^{\circ} \mathrm{C}$ until assessments of chemokine levels (a maximum period of three months). Serum level of CXCL8, CXCL10 and CXCL16 was assessed by indirect sandwich enzyme linked immunosorbent assay (ELISA), using commercially available kits (PeproTech, United Kingdom), and instructions of manufacture were followed. Briefly, anti-human CXCL8, CXCL10 or CXCL16 coating antibody (capture antibody) was adsorbed onto wells of 96well plate. Then, serum or standard was added to the respective wells, and after an incubation period, a biotinylated anti-human chemokine antibody was added (detection antibody). Following a further incubation, unbound biotinylated anti-human chemokine antibody was removed during a wash step, and avidin horseradish peroxidase (HRP) conjugate was then added. Following incubation, unbound avidin-HRP conjugate was removed during a wash step, and a substrate solution reactive with HRP was added to the wells. A colored product was formed in proportion to the amount of human chemokine present in the sample or standard. The color development was monitored with ELISA plate reader and absorbance was measured at a wavelength of $405 \mathrm{~nm}$. A standard curve was prepared from standard dilutions and human chemokine level was determined using a curve fitting equation.

\section{Statistical analysis:}

After normality testing of original data, chemokine serum levels were given as medians and ranges. Statistically significant differences between medians were assessed by the nonparametric MannWhitney $U$ test. Binary logistic regression (BLR) analysis was performed to determine the role of chemokine serum levels as predictors of the outcome variables (BC or BBL) and their associated odds ratios (ORs). In addition, receiver operating characteristic (ROC) analysis was calculated and the area under curve (AUC), sensitivity and specificity were estimated for each chemokine. An exact two-tailed probability value $(p) \leq 0.05$ was considered significant. The false discovery rate (FDR) was applied to correct the $p$-value for multiple comparisons. The statistical package SPSS version 19 was used to carry out these analyses.

\section{Results:}

The three investigated chemokines showed a significant increased serum level median in BC and BBL patients compared to control (CXCL8: 47.3 and 25.7 vs. 15.0; CXCL10: 37.6 and 30.7 vs. 13.1; CXCL16; 27.9 and 25.2 vs. $19.2 \mathrm{pg} / \mathrm{ml}$, respectively). The same observation was also made when BC patients were compared to BBL patients, with the exception of CXCL16, which showed no significant difference between the two groups of patients (Table 2).

Table 2. Serum level of CXCL8, CXCL10 and CXCL16 among breast cancer and benign breast lesion patients and control.

\begin{tabular}{lcccccc}
\hline \multirow{2}{*}{ Chemokine } & \multicolumn{3}{c}{ Median $(\mathrm{range} ; \mathrm{pg} / \mathrm{ml})$} & \multicolumn{3}{c}{$p$-value } \\
\cline { 2 - 7 } & $\mathrm{BC}(\mathrm{N}=45)$ & $\mathrm{BBL}(\mathrm{N}=28)$ & Control $(\mathrm{N}=20)$ & BC $v s$. & BC $v s$. & BBL $v s$. \\
CXCL8 & $47.3(36.9-62.8)$ & $25.7(19.1-33.7)$ & $15.0(7.5-38.0)$ & $<0.001$ & $<0.001$ & $<0.001$ \\
CXCL10 & $37.6(28.9-50.8)$ & $30.7(20.7-40.6)$ & $13.1(8.9-50.0)$ & $<0.001$ & $<0.001$ & $<0.001$ \\
CXCL16 & $27.9(16.9-46.1)$ & $25.2(12.8-44.9)$ & $19.2(13.7-25.5)$ & 0.621 & $<0.001$ & 0.002 \\
\hline
\end{tabular}

BC: Breast cancer; BBL: Benign breast lesion, N: Number, $p$-value: Mann-Whitney $U$ test corrected probability (two-tailed).

Inspecting serum levels of CXCL8, CXCL10 and CXCL16 in BC patients distributed by clinical stage and immunohistochemical expression of ER, PgR and HER-2 receptors revealed that clinical stages showed no significant variations in the distribution of the three chemokine medians, while two significant differences were observed when the expression of receptors were considered. Triple- negative patients showed a significant increased level of CXCL8 compared to patients who were positive for at least one receptor (56.2 vs.45.9 $\mathrm{pg} / \mathrm{ml}$ ). The second difference was observed in HER-2+ve patients. They were presented with a significant increased level of CXCL16 compared HER-2-ve patients (32.2 vs.22.3 pg/ml) (Table 3). 
Table 3. Serum level of CXCL8, CXCL10 and CXCL16 among breast cancer patients distributed according to clinical stage and immunohistochemical expression of estrogen, progesterone and human epidermal growth factor receptor-2 receptors.

\begin{tabular}{|c|c|c|c|}
\hline \multirow[t]{2}{*}{ Group } & \multicolumn{3}{|c|}{ Median (Range) } \\
\hline & CXCL8 (pg/ml) & CXCL10 (pg/ml) & CXCL16 $(\mathrm{pg} / \mathrm{ml})$ \\
\hline \multicolumn{4}{|l|}{ Clinical stage } \\
\hline I, II & $45.9(40.4-62.8)$ & $34.9(30.4-45.9)$ & $30.1(17.9-46.1)$ \\
\hline III & $48.4(36.9-56.7)$ & $42.9(28.9-50.8)$ & $26.4(16.9-44.9)$ \\
\hline$p$-value & 0.980 & 0.099 & 0.373 \\
\hline \multicolumn{4}{|l|}{$E R$} \\
\hline ER+ve & $45.8(36.9-54.2)$ & $39.9(30.4-50.8)$ & $27.4(16.9-46.1)$ \\
\hline ER-ve & $50.3(40.8-62.8)$ & $35.7(28.9-50.3)$ & $29.9(19.5-44.1)$ \\
\hline$p$-value & 0.087 & 0.323 & 0.956 \\
\hline \multicolumn{4}{|l|}{ PgR } \\
\hline PgR+ve & $45.3(36.9-54.2)$ & $38.8(30.4-50.8)$ & $27.7(16.9-46.1)$ \\
\hline PgR-ve & $49.9(39.6-62.8)$ & $36.8(28.9-50.3)$ & $27.9(19.5-44.1)$ \\
\hline$p$-value & 0.141 & 0.835 & 0.882 \\
\hline \multicolumn{4}{|l|}{ HER-2 } \\
\hline HER-2+ve & $47.4(36.9-53.4)$ & $38.2(28.9-50.8)$ & $32.2(19.5-46.1)$ \\
\hline HER-2-ve & $47.3(40.1-62.8)$ & $37.6(30.4-50.8)$ & $22.3(16.9-43.8)$ \\
\hline$p$-value & 0.757 & 0.640 & 0.006 \\
\hline \multicolumn{4}{|l|}{ Total Expression } \\
\hline Triple-negative & $56.2(51.4-62.8)$ & $41.7(35.7-50.3)$ & $28.3(20.6-33.9)$ \\
\hline Positived & $45.9(36.9-54.2)$ & $36.8(28.9-50.8)$ & $27.9(16.9-46.1)$ \\
\hline$p$-value & 0.001 & 0.203 & 0.832 \\
\hline
\end{tabular}

BLR analysis was performed to analyze the comparison between outcome categories by taking control as a reference category. BC, BBL, and control categories were considered as dependent variables, while chemokine serum levels (CXCL8, CXCL10, and CXCL16) were the predictors that were used to inspect which variable significantly predicts the outcome. With respect clinical stages of $\mathrm{BC}$, stage I, II was considered the reference category. In the case of immunohistochemical expression of ER and $\mathrm{PgR}$ receptors, patients positive for these markers were the reference category, while for HER-2, it was HER-2-ve patients. The assumed model that significantly fit the data was analyzed with chi-square test. The analysis revealed that CXCL8 predicted the outcome variables $\mathrm{BC}(\mathrm{OR}=1.21 ; 95 \% \mathrm{CI}: 1.05-$ $1.40 ; p$-value $=0.011)$ and $\mathrm{BBL}(\mathrm{OR}=1.23 ; 95 \%$ CI: $1.03-1.46 ; p$-value $=0.024)$. CXCL8 prediction was more pronounced in $\mathrm{BC}$ patients with a negative expression of ER and PgR, especially triple-negative patients $(\mathrm{OR}=2.51 ; 95 \%$ CI: $1.02-6.19 ; p$-value $=0.046)$. BBL had a further predictor that was CXCL10 (OR: 1.14; 95\% CI: $1.03-1.2 ; p$-value $=0.012)$. The latter chemokine was also associated with a significant OR in clinical stage III patients $(\mathrm{OR}=1.19 ; 95 \% \mathrm{CI}: 1.02-1.37$; $p$-value $=0.026)$. CXCL16 was only observed to have a significant $\mathrm{OR}$ in HER-2+ve patients $(\mathrm{OR}=$ 1.13; 95\% CI: $1.03-1.23$; $p$-value $=0.007)($ Table 4).

Table 4. Binary logistic regression analysis of CXCL8, CXCL10 and CXCL16 serum levels as predictor variables in breast cancer and benign breast lesion patients as outcome variables.

\begin{tabular}{lcccccc}
\hline \multicolumn{1}{c}{ Category* } & \multicolumn{2}{c}{ CXCL8 } & \multicolumn{3}{c}{ CXCL10 } & \multicolumn{2}{c}{ CXCL16 } \\
\cline { 2 - 7 } Total BC & OR $(95 \%$ CI) & $p$-value & OR (95\% CI) & $p$-value & OR (95\% CI) & $p$-value \\
Clinical stage III & $1.21(1.05-1.40)$ & 0.011 & $1.12(0.97-1.28)$ & 0.113 & $1.09(0.86-1.38)$ & 0.480 \\
ER-ve & $0.96(0.84-1.10)$ & 0.541 & $1.19(1.02-1.37)$ & 0.026 & $0.94(0.86-1.04)$ & 0.220 \\
PgR-ve & $1.23(1.03-1.46)$ & 0.021 & $0.90(0.80-1.03)$ & 0.116 & $0.99(1.90-1.08)$ & 0.737 \\
HER-2+ve & $1.16(1.01-1.34)$ & 0.039 & $0.98(0.88-1.09)$ & 0.735 & $0.98(0.90-1.06)$ & 0.588 \\
Triple-negative & $0.94(0.82-1.06)$ & 0.295 & $1.02(0.91-1.14)$ & 0.757 & $1.13(1.03-1.23)$ & 0.007 \\
BBL & $2.51(1.02-6.19)$ & 0.046 & $1.08(0.77-1.51)$ & 0.654 & $0.88(0.65-1.18)$ & 0.389 \\
\hline BC: Breast cancer; ER: Estrogen; PgR: Progesterone; HER-2: Human epidermal growth factor receptor-2; -ve: Negative; BBL: \\
Benign breast lesion; OR: Odds ratio; CI: Confidence interval, $p$ = Probability. *ontrol was the reference category for total BC and \\
BBL, while for BC subgroups; the corresponding subgroup was the reference category.
\end{tabular}


When the ROC analysis was carried out, an AUC value greater than 0.9 was recorded for CXCL8 and CXCL10 in BC patients (0.998 and 0.923, respectively), while among BBL patients, it

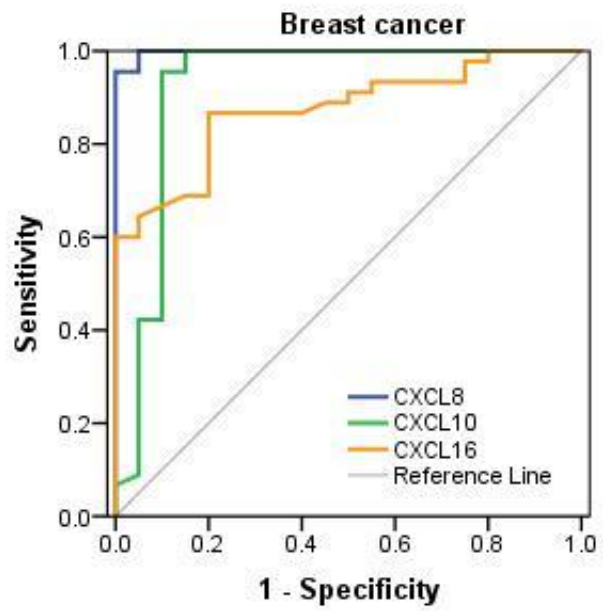

was for CXCL8 only (0.902). The highest sensitivity and specificity were estimated for CXCL8 in BC patients (95.6 and $95.0 \%$, respectively) (Fig. 1 and Table 5).

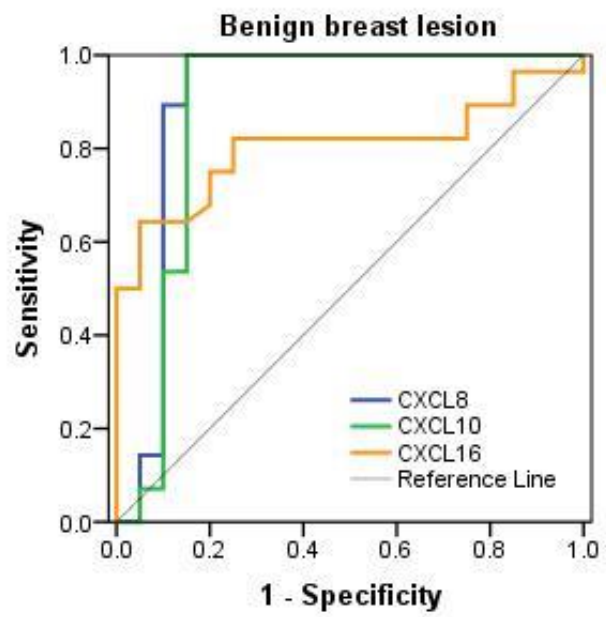

Figure 1. Receiver operating characteristic curve (area under curve; AUC) of CXCL8, CXCL10 and CXCL16 serum levels among breast cancer and benign breast lesion patients versus control.

Table 5. Receiver operating characteristic analysis of CXCL8, CXCL10 and CXCL16 serum levels among breast cancer and benign breast lesion patients versus control.

\begin{tabular}{lcccccc}
\hline \multirow{2}{*}{ Variable } & \multicolumn{3}{c}{ Breast Cancer } & \multicolumn{3}{c}{ Benign Breast Lesion } \\
\cline { 2 - 7 } AUC & CXCL8 & CXCL10 & CXCL16 & CXCL8 & CXCL10 & CXCL16 \\
SE & 0.998 & 0.923 & 0.874 & 0.902 & 0.880 & 0.804 \\
$p$-value & 0.003 & 0.052 & 0.043 & 0.063 & 0.067 & 0.065 \\
95\% CI & $<0.001$ & $<0.001$ & $<0.001$ & $<0.001$ & $<0.001$ & $<0.001$ \\
Cut-off value & $0.992-1.000$ & $0.821-1.000$ & $0.790-0.958$ & $0.779-1.000$ & $0.748-1.000$ & $0.677-0.932$ \\
Sensitivity (\%) & 37.7 & 31.3 & 21.8 & 21.4 & 22.3 & 20.1 \\
Specificity (\%) & 95.6 & 91.1 & 80.0 & 89.3 & 89.3 & 82.1 \\
\hline
\end{tabular}

AUC: Area under curve; CI: Confidence interval; SE: Standard error under the nonparametric assumption; $p$ : Probability for null hypothesis (true area $=0.5$ ).

\section{Discussion:}

The presented results suggest the predictive significance of CXCL8 and CXCL10 as biomarkers for $\mathrm{BC}$ and $\mathrm{BBL}$; being more evident in malignant lesions. Earlier studies indicated relevant findings and these chemokines have been reported to be associated with a progression of the female breast malignancy [9-15]. However, two observations are of note in present study: significant increased levels of CXCL8 in triple-negative and CXCL16 in HER$2+$ ve $\mathrm{BC}$ patients.

With respect to cancer, two opposite functional roles of CXCL8 have been suggested; it enhances the immunoregulatory potentials against carcinogenesis, and can also modify the tumor microenvironment to enhance tumourigenesis. The latter role is more dominant in $\mathrm{BC}$ compared to the former because $\mathrm{BC}$ cells have been found to express two receptors (CXCR1 and CXCR2) for CXCL8 (17). The interaction between CXCL8 and its cognate receptors has been associated with initiation and development of BC. In addition, it has been reported that an increased level of CXCL8 is mostly detected in patients exhibiting the ER-ve, PgR-ve and HER-2-ve phenotypes (18). An observation that is strongly enhanced by the present study results, whereby patients displaying the triple-negative subtype demonstrated a significant increased serum level of CXCL8 compared to patients positive for one or more of these receptors. In this context, it has been found that a down-regulation of CXCL8 was associated with a significant reduction in the density of micro-vessels in ER-ve BC patients (19).

The significance of CXCL8 as a biomarker for $\mathrm{BC}$ was further examined when the BLR and ROC analyses was performed. The former analysis suggests the predictive significance of CXCL8 in the progression of $\mathrm{BC}$, especially triple-negative patients, in whom the OR recorded a value of 2.51 . The estimated AUC (0.998) of ROC analysis confirmed such significance, and may suggest a pathological role for CXCL8 in BC. Such role has been previously explored in term of tumor 
neovascularization, which contributes to initiation and growth of BC and the supply of blood for distant metastasis. The stimulated ectopic expression of CXCL8 by interleukin-1beta (IL-1 $\beta$ ) and tumor necrosis factor-alpha (TNF- $\alpha$ ) were associated with an enhancement of metastasis in $\mathrm{BC}$; as high CXCL8 level can promote angiogenesis and attract more neutrophils to the site of tumor. The released enzymes from these cells have been involved in tissue remodelling and BC establishment (20). Accordingly, the significance of CXCL8 in the initiation, progression, angiogenesis and metastasis of BC cannot be underestimated, and such cytokine has been defined as an unfavorable prognostic factor (21).

Serum level of CXCL10 was also significantly higher in patients with $\mathrm{BC}$ compared to those with BBL or healthy individuals. Different cells can release CXCL10 (for instance, granulocytes, monocytes, keratinocytes, epithelial and endothelial cells) in response to IFN- $\gamma$ (11). However, tumor cells are also a further major source of CXCL10 and this may explain the increased serum levels of such chemokine in more advanced BC stages (6), as in the present study, in which stage III patients were observed to have the highest level of CXCL10 but the difference was not significant compared to stages I and II. It has also been demonstrated that CXCL10 and its receptor (CXCR3) shows a strong expression in $\mathrm{BC}$ and its secretion is IFN- $\gamma$-mediated in a dose-dependent manner. By such co-expression, CXCL10 exerts an autocrine effect on tumor cells to promote tumor invasiveness and progression (11). GoldbergBittman and colleagues studied the expression of CXCL10 and its receptor on BC cell lines, and reported that malignant cancer cells express larger quantities of such chemokine and its receptor (22). The concomitant expression of CXCR3 and CXCL10 by the same BC cells suggest that the CXCR3-CXCL10 axis may function in these cells in an autocrine manner and result in tumor cells invasion and metastasis (13). It has been also indicated that CXCL10 promote matrix metalloproteinase secretion in colorectal carcinoma cells and thus enhancing the malignancy of the tumor microenvironment (23). A similar pathway may also occur in $\mathrm{BC}$ and promote the effects of CXCL10 on tumor progression.

CXCL16 is the third chemokine that showed a significant increased serum level in both types of tumors (BC and BBL). The cognate receptor for CXCL16 is CXCR6, and there is increasing evidence that suggests that CXCL16/CXCR6 axis plays prominent roles in progression of a variety of cancers. Such axis has been found to have a role in regulating the migration and proliferation of cancer cells, as well as angiogenesis (14). It has been demonstrated that CXCL16 and CXCR6 show a significantly increased expression in $\mathrm{BC}$ tissues compared to normal breast, and such expression was positively correlated with the progression of this malignancy. In contrast, a down-regulation of CXCR6 expression reduced its effects, which was associated with HER-2+ve expression (15). Actually, the present $\mathrm{BC}$ patients were observed to have a significant increased serum level of CXCL16 in those showing HER-2+ve over-expressions compared to HER-2-ve patients, and therefore its potential in such group of patients has to be further inspected especially at the molecular level.

The deviated chemokines (CXCL8 in triplenegative BC and CXCL16 in HER-2+ve BC) might promote growth of tumor cells or enhance the potential of metastasis. A differential analysis of chemokine expression in BC cells is therefore suggested. Because, it has been augmented that tumor cells take the advantage of chemokine expression and their receptors to induce tumor growth and angiogenesis, alter tumor microenvironment and potentiate metastasis (9-12). Thus, the observed increased serum level of CXCL8 and CXCL10 may contribute to progression of BC and may also serve as biomarker for prognosis and response to therapy.

\section{Conclusion:}

CXCL8, CXCL10 and CXCL16 are important chemokines that can be considered as biomarkers for the progression of $\mathrm{BC}$, especially when the immunohistochemical expression of ER, PgR and HER-2 is considered (CXCL8 and CXCL16). In this context, the predictive significance of CXCL8 as a marker for the progression of BC is suggested, especially in triplenegative patients. However, the results of present study were limited by the sample size of patients and control.

\section{Acknowledgment:}

The cooperation of the medical staff at the Oncology Teaching Hospital in Baghdad is appreciated.

\section{Conflicts of Interest: None.}

\section{The author has signed on animal welfare statement.}

\section{References:}

1. Ghoncheh M, Pournamdar Z, Salehiniya H. Incidence 
and mortality and epidemiology of breast cancer in the world. Asian Pac J Cancer Prev. 2016;17(S3):436.

2. Alwan NAS. Breast cancer among Iraqi women: preliminary findings from a regional comparative breast cancer research project. J Glob Oncol. 2016;2(5):255-8.

3. Sun YS, Zhao Z, Yang ZN, Xu F, Lu HJ, Zhu ZY, et al. Risk factors and preventions of breast cancer. Int $\mathbf{J}$ Biol Sci. 2017;13:1387-97.

4. Wang M, Zhang C, Song Y, Wang Z, Wang Y, Luo $\mathrm{F}$, et al. Mechanism of immune evasion in breast cancer. Onco Targets Ther. 2017;10:1561-73.

5. Abroun S. Chemokines in homeostasis and cancers. Yakhteh Med J. 2008;10(3):155-66.

6. Palacios-Arreola MI, Nava-Castro KE, Castro JI, García-Zepeda E, Carrero JC, Morales-Montor J. The role of chemokines in breast cancer pathology and its possible use as therapeutic targets. J Immunol Res. 2014;2014(Article ID 849720): 8 pages.

7. Mohamed MM, Al-Raawi D, Sabet SF, El-Shinawi M. Inflammatory breast cancer: New factors contribute to disease etiology: A review. J Adv Res. 2014;5(5):525-36.

8. Singh JK, Simões BM, Howell SJ, Farnie G, Clarke RB. Recent advances reveal IL-8 signaling as a potential key to targeting breast cancer stem cells. Breast Cancer Res. 2013;15(4):210.

9. Liu Q, Li A, Tian Y, Wu JD, Liu Y, Li T, et al. The CXCL8-CXCR1/2 pathways in cancer. Cytokine Growth Factor Rev. 2016;31:61-71.

10. Fleisher B, Clarke C, Ait-Oudhia S. Current advances in biomarkers for targeted therapy in triple-negative breast cancer. Breast Cancer Targets Ther. 2016; 8:183-97.

11. Mulligan AM, Raitman I, Feeley L, Pinnaduwage D, Nguyen LT, O'Malley FP, et al. Tumoral lymphocytic infiltration and expression of the chemokine CXCL10 in breast cancers from the Ontario Familial Breast Cancer Registry. Clin Cancer Res. 2013;19(2):336-46.

12. Espinoza JA, Jabeen S, Batra R, Papaleo E, Haakensen V, Timmermans Wielenga V, et al. Cytokine profiling of tumor interstitial fluid of the breast and its relationship with lymphocyte infiltration and clinicopathological characteristics. Oncoimmunology. 2016;5(12):e1248015.

13. Jafarzadeh A, Fooladseresht H, Nemati M,
Assadollahi Z, Sheikhi A, Ghaderi A. Higher circulating levels of chemokine CXCL10 in patients with breast cancer: Evaluation of the influences of tumor stage and chemokine gene polymorphism. Cancer Biomark. 2016;16(4):545-54.

14. Fang Y, Henderson FC, Yi Q, Lei Q, Li Y, Chen N, et al. Chemokine CXCL16 expression suppresses migration and invasiveness and induces apoptosis in breast cancer cells. Mediators Inflamm. 2014;2014:478641.

15. Xiao G, Wang X, Wang J, Zu L, Cheng G, Hao M, et al. CXCL16/CXCR6 chemokine signaling mediates breast cancer progression by pERK1/2-dependent mechanisms. Oncotarget. 2015;6(16):14165-78.

16. Park YH, Lee SJ, Cho EY, Choi YL, Lee JE, Nam SJ, et al. Clinical relevance of TNM staging system according to breast cancer subtypes. Ann Oncol. 2011;22(7):1554-60.

17. Zuccari DAP de C, Leonel C, Castro R, Gelaleti GB, Jardim BV, Moscheta MG, et al. An immunohistochemical study of interleukin-8 (IL-8) in breast cancer. Acta Histochem. 2012;114(6):571-6.

18. Lin Y, Huang R, Chen L, Li S, Shi Q, Jordan C, et al. Identification of interleukin-8 as estrogen receptorregulated factor involved in breast cancer invasion and angiogenesis by protein arrays. Int $\mathbf{J}$ Cancer. 2004;109(4):507-15.

19. Yao C, Lin Y, Chua M-S, Ye C-S, Bi J, Li W, et al. Interleukin-8 modulates growth and invasiveness of estrogen receptor-negative breast cancer cells. Int $\mathbf{J}$ cancer. 2007;121(9):1949-57.

20. De Larco JE, Wuertz BR, Rosner KA, Erickson SA, Gamache DE, Manivel JC, et al. A potential role for interleukin- 8 in the metastatic phenotype of breast carcinoma cells. Am J Pathol. 2001;158(2):639-46.

21. Liu Q, Li A, Tian Y, Wu JD, Liu Y, Li T, et al. The CXCL8-CXCR1/2 pathways in cancer. Cytokine Growth Factor Rev. 2016;31:61-71.

22. Goldberg-Bittman L, Neumark E, Sagi-Assif O, Azenshtein E, Meshel T, Witz IP, et al. The expression of the chemokine receptor CXCR3 and its ligand, CXCL10, in human breast adenocarcinoma cell lines. Immunol Lett. 2004;92(1-2):171-8.

23. Zipin-Roitman A, Meshel T, Sagi-Assif O, Shalmon B, Avivi C, Pfeffer RM, et al. CXCL10 promotes invasion-related properties in human colorectal carcinoma cells. Cancer Res. 2007;67(7):3396-405. 
الاهمية الواسم-حياتية للحركيات الكيميائية المصلية 8 و10 و16 لاورام الثدي في مريضات عراقيات

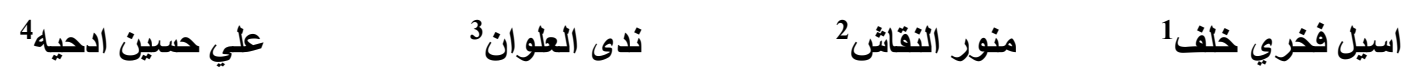

1 قسم التقنيات الاحيائية، كلية العلوم، جامعة بغداد، بغداد، العراق.

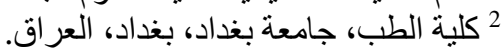

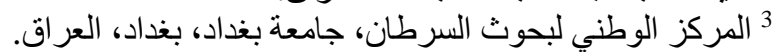

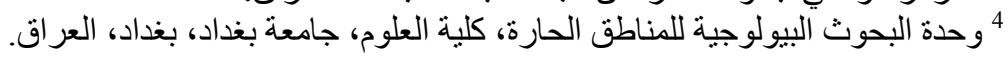

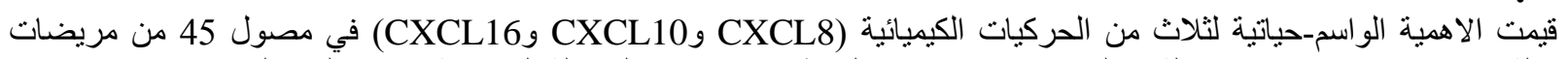

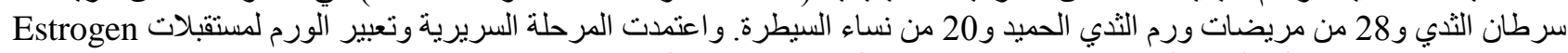

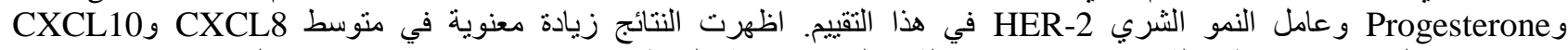

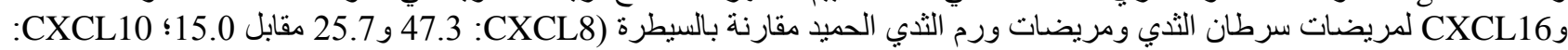
37.6 و30.7 مقابل 13.1؛

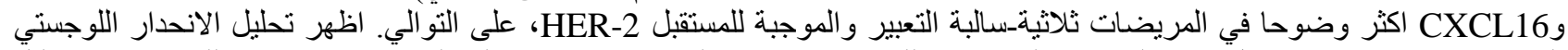

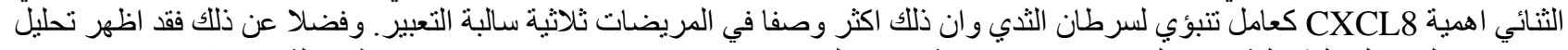

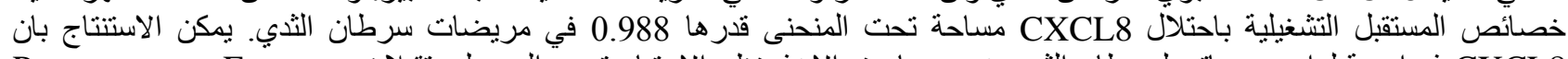

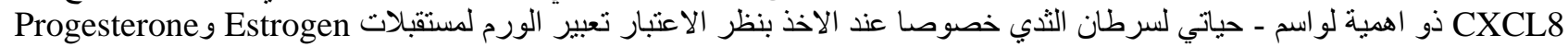
و عامل النمو الثري HER-2. وفي هذا الصدد، فان الدراسة تقترح الاهمية التنبؤية للحركي الكيميائي-8 في تطور سرطان الثيني لدى المريضات ثلاثية سألبة التعبير.

الكلمات المفتاحية: سرطان الثدي، ورم الثدي الحميد، الحركيات الكيميائية 8 و10 و16. 